\title{
Early Detection of Left Ventricular Subclinical Systolic Dysfunction in Hypertensive Patients: Speckle Tracking at Rest and after Dobutamine Stress Echocardiography Study
}

\author{
Ahmed Mohamed Rabea Rezk'1, M.B.B.Ch; Abdel-Hamid Ismail Abu-Rahal', MD; \\ Abdelmaksoud Al-Ganady ${ }^{1}$, MD; Mohamed Mahmoud ${ }^{1}$, MD; Mansour Mohamed Sallam¹, MD
}

CorrespondingAuthor:

Ahmed Mohame Rabea

drahmedrabee3@gmail.com

Received for publication, May 2, 2020; Accepted, June 9, 2020; published online, June 9, 2020.

Copyright 2020 The Authors published by Al-Azhar University, Faculty of Medicine, Cairo, Egypt. All rights reserved. This an openaccess article distributed under the legal terms, where it is permissible to download and share the work provided it is properly cited. The work cannot be changed in anyway or used commercially.

doi:10.21608/aimj.2020.24523.1151

${ }^{1}$ Department $\quad$ of
Cardiovascular, Faculty of
Medicine-Al-Azhar University

\begin{abstract}
Background: Hypertension is one of the major cardiovascular risk factor that may result in heart failure. Two-D transthoracic echocardiography (2D TTE) recognizes reduction in left ventricular systolic function in late stages of the disease course, so early detection is of paramount importance.

Aim of the work: Our study intended to evaluate feasibility of speckletracking echocardiography (STE) to provide additional perceptions for early detection of hypertension induced left ventricular systolic dysfunction.
\end{abstract}

Patient and Methods: We enrolled 40 hypertensive patients, 21 women $(52.5 \%)$ their mean age was $54.55 \pm 9$ years and 20 normotensive age and gender matched control individuals (10 women, their mean age was $53.20 \pm 12.06$ years). All had normal left ventricular systolic function by 2 D TTE. STE performed at rest and low dose dobutamine. Patients with significant ischemic or valvular heart disease as well as atrial fibrillation, conduction abnormalities and diabetes excluded.

Results: Systolic blood pressure was significantly higher in the hypertensive group patients $(138.50 \pm 10.27 \mathrm{mmHg}$ vs. $120.50 \pm 7.76$ $\mathrm{mmHg}$, respectively; $\mathrm{P}=<0.001)$. Compared to control group, hypertensive patients experienced significantly impaired global longitudinal STE at rest $(-18.08 \pm 1.63 \%$ versus $20.50 \pm 1.52 \%$ respectively; $\mathrm{P}<0.001)$ and at low-dose dobutamine $(-19.11 \pm 1.75 \%$ versus $22.61 \pm 1.88 \%$ respectively; $\mathrm{P}<0.008$ )

Conclusion: Speckle tracking echocardiography increases the sensitivity in detecting subclinical cardiac involvement in early stages of hypertension compared to conventional 2-D echocardiography.

Keywords: Hypertension; Ventricular Function; Global Longitudinal Strainp; Dobutamine Echocardiography.

Disclosure: The authors have no financial interest to declare in relation to the content of this article. The Article Processing Charge was paid for by the authors.
Introduction

Hypertension is a prevalent and well recognized cardiovascular risk factor, which may lead to left ventricular (LV) systolic impairment through chronic pressure overload. LV hypertrophy (LVH) is a compensatory process in response to increased wall stress. However, this initially useful adaptive mechanism later becomes 'a pathological change' in the myocardium. Whilst LVH has been shown to be a powerful independent predictor for cardiovascular morbidity and mortality it can occur late in the course of the disease. ${ }^{1}$

Multiple recent studies have shown that LV ejection fraction (LVEF) lacks accuracy and sensitivity in detecting early subclinical impairment. In contrast, several studies using two- dimensional (2D) speckletracking echocardiography (STE) have demonstrated that despite normal LVEF, many patients in different clinical settings have longitudinal systolic dysfunction of the left ventricle. Thus, systolic analysis of the left ventricle using global longitudinal systolic strain has been suggested as a new standard assessment for global LV systolic function . ${ }^{2}$

Dobutamine Stress echocardiography allows for the dynamic evaluation of cardiac structure and function by increasing heart rate, cardiac output, and myocardial oxygen demand. While exercise stress echocardiography provides physiologic information, echocardiographic imaging in pharmacologic stress tests is facilitated by the lack of both exercise-related chest wall motion and increased respirations. ${ }^{3}$

Dobutamine Stress echocardiography was used in our study to assess the contractile reserve (CR) of hypertensive patients which is thought to represent an early manifestation of LV systolic dysfunction. ${ }^{4}$ 
Our study designated to detect the value of assessment of left ventricular function by measuring global longitudinal strain at rest and after dobutamine stress for detection of early subclinical left ventricular systolic dysfunction in patients with systemic hypertension.

\section{Patient and Methods}

We enrolled 40 known hypertensive patients and 20 normotensive age and gender matched control individuals admitted at Al-Hussain University Hospital, Cairo, between June 2019 and April 2020, The hypertensive group of patients had been selected after elective invasive assessment of their coronaries for another reason than the research, coronary angiograms proved evidence of no or non-significant coronary artery disease.

An informed consent obtained from every patient after explanation of the research objectives and the purpose of this study.

Exclusion criteria: Patients with significant coronary artery disease, defined as $>50 \%$ stenosis in any major epicardial coronary artery or its major branches on coronary angiography.

Previous myocardial infarction or coronary revascularization. Non-sinus rhythm as atrial fibrillation. Left bundle branch block. Coexisting significant left sided valvular heart disease (more than mild in severity). Diabetes mellitus.

The following data were collected for each patient:

Clinical Data: Patients' data as gender, age, weight, height, hypercholesterolemia, smoking status, family history of ischemic heart disease and drug history. Clinical data as heart rate, systolic and diastolic blood pressures at rest and at low dose dobutamine. Betablockers held 48 hours before the echocardiographic study .

ECG: Standardized 12 lead ECG recorded in every participant in the study. Systematic interpretation and recording of ECG data accomplished for documentation of rhythm, heart rate, presence or absence of left ventricular hypertrophy, conduction disturbances or manifestation of ischemic heart disease.

Echocardiography: All subjects were examined at rest in the left lateral decubitus position to obtain adequate images in different standard views with a ultrasound machine using. Echocardiographic data were collected as follow: (A) Resting conventional 2D echocardiography: A comprehensive transthoracic echocardiogram with appropriate 2D, color, and Doppler imaging was performed. Enddiastolic and end-systolic dimensions of the LV, enddiastolic thickness of inter-ventricular septum and LV posterior wall, LV Ejection fraction (derived from linear measurements obtained from 2D images), LV wall thickness, LV mass were measured 5. (B) Dobutamine stress echocardiography: Dobutamine stress echocardiography was performed in all participants according to standard protocol. Intravenous dobutamine was infused in incremental doses starting at five $\mu \mathrm{g} / \mathrm{kg} / \mathrm{min}$. The dose then increased to $10 \mu \mathrm{g} / \mathrm{kg} / \mathrm{min}$ and $20 \mu \mathrm{g} / \mathrm{kg} / \mathrm{min}$ at three $3.14 \pm 0.39 \mathrm{~cm}$ respectively; $\mathrm{P}=0.386$ ) (Figure 3 ). min interval, these doses were chosen as they have been previously demonstrated to be safe and effective in detecting contractile reserve, without affecting heart rate, blood pressure,or loading conditions 6 . Standard parasternal long- and short-axis views, and apical four-, two-, and three-chamber views of the left ventricle obtained at rest and at the end of each infusion stage 6 . Visual wall motion analysis was performed by an experienced investigator using the American Society of Echocardiography's 17segment model in blinded fashion. ${ }^{5}$ (C) Twodimensional speckle tracking global longitudinal strain: The speckle tracking strain analyses was performed on grey scale images of the left ventricle. Peak global systolic longitudinal strain was measured from the 18 segment measurements (six segments from each of the apical four-, two-, and threechamber views) at rest and at low dose dobutamine stress. During strain analysis, the endocardial border was manually traced at end-systole, and the width of the region of interest was manually adjusted to include the entire myocardial wall thickness. Three cardiac cycles were analysed and the measurements were averaged. ${ }^{5}$

Statistical analysis:

Results of the present study were statistically analysed using SPSS 25 (IBM, USA). Data were represented as median (interquartile range) or number and percentage. Numerical data were compared using Mann- Whitney $U$ test while categorical data were compared using Fisher exact test or Chi-square test as appropriate. ROC curve was used to evaluate the performance of different tests differentiate between certain groups. The level of significance was taken at $\mathrm{P}$ value $<0.050$ is significant, otherwise is non-significant.

\section{Results}

The resting mean SBP and DBP was significantly higher in the patients group compared to the control group either at rest (SBP; $138.50 \pm 10.27 \mathrm{mmHg}$ vs. $120.50 \pm 7.76 \mathrm{mmHg}$, respectively; $\mathrm{P}=<0.001$, DBP; $84.13 \pm 8.54 \mathrm{mmHg}$ vs. $77.75 \pm 6.17 \mathrm{mmHg}$ respectively; $\mathrm{P}=0.004)$, or at low dose dobutamine (SBP; $140.50 \pm 9.18 \mathrm{mmHg}$ vs. $121.75 \pm 10.29 \mathrm{mmHg}$, respectively; $\mathrm{P}=<0.001$, DBP; $83.63 \pm 9.47 \mathrm{mmHg}$ vs. $76.75 \pm 5.91 \mathrm{mmHg}$ respectively; $\mathrm{P}=0.004)$. The mean HR didn't differ significantly between the patients and control groups either at rest $(75.60 \pm 10.50 \quad \mathrm{BPM}$ vs. $74.90 \pm 8.04 \quad \mathrm{BPM}$ respectively; $\mathrm{P}=0.477$ ), or at low dose dobutamine $(77.30 \pm 11.76 \quad \mathrm{BPM}$ vs. 76.00 \pm 6.98 BPM, respectively; $\mathrm{P}=0.350$ ), (Figure 1,2 ).

Both the mean of the inter-ventricular septum (IVS) and LV posterior wall (LVPW) thickness were significantly higher in the patients group compared to the control group (IVS; $1.20 \pm 0.13 \mathrm{~cm}$ vs. $0.90 \pm 0.17$ $\mathrm{cm}$ respectively; $\mathrm{P}<0.001$, LVPW; $1.22 \pm 0.10 \mathrm{~cm}$ vs. $0.89 \pm 0.15 \mathrm{~cm}$ respectively; $\mathrm{P}<0.001$ ), with no difference in the mean of LVIDd and LVIDs between the patients group compared to control group (LVIDd; $4.68 \pm 0.54 \mathrm{~cm}$ vs. $4.83 \pm 0.46 \mathrm{~cm}$, respectively; $\mathrm{P}=0.297$, LVIDs; $3.07 \pm 0.50 \mathrm{~cm}$ vs.

There was no significant difference in the mean LVEF between the patients group and the control 
group either at rest $(61.82 \pm 5.08 \%$ and $61.43 \pm 4.41 \%$ respectively; $\mathrm{P}=0.771$ ) or at low dose dobutamine $(65.46 \pm 5.08 \%$ and $64.35 \pm 5.68 \%$ respectively; $\mathrm{P}$ $=0.311$ ), while LV GLS was significantly lower in the patients group compared to the control group at rest $(-18.08 \pm 1.63 \%$ vs. $-20.50 \pm 1.52 \%$ respectively;
$\mathrm{P}<0.001)$ and at low dose dobutamine $(-19.11 \pm 1.75$ \%vs. $-22.61 \pm 1.88 \%$ respectively; $\mathrm{P}=0.008)$ (Tables $1,2)$.

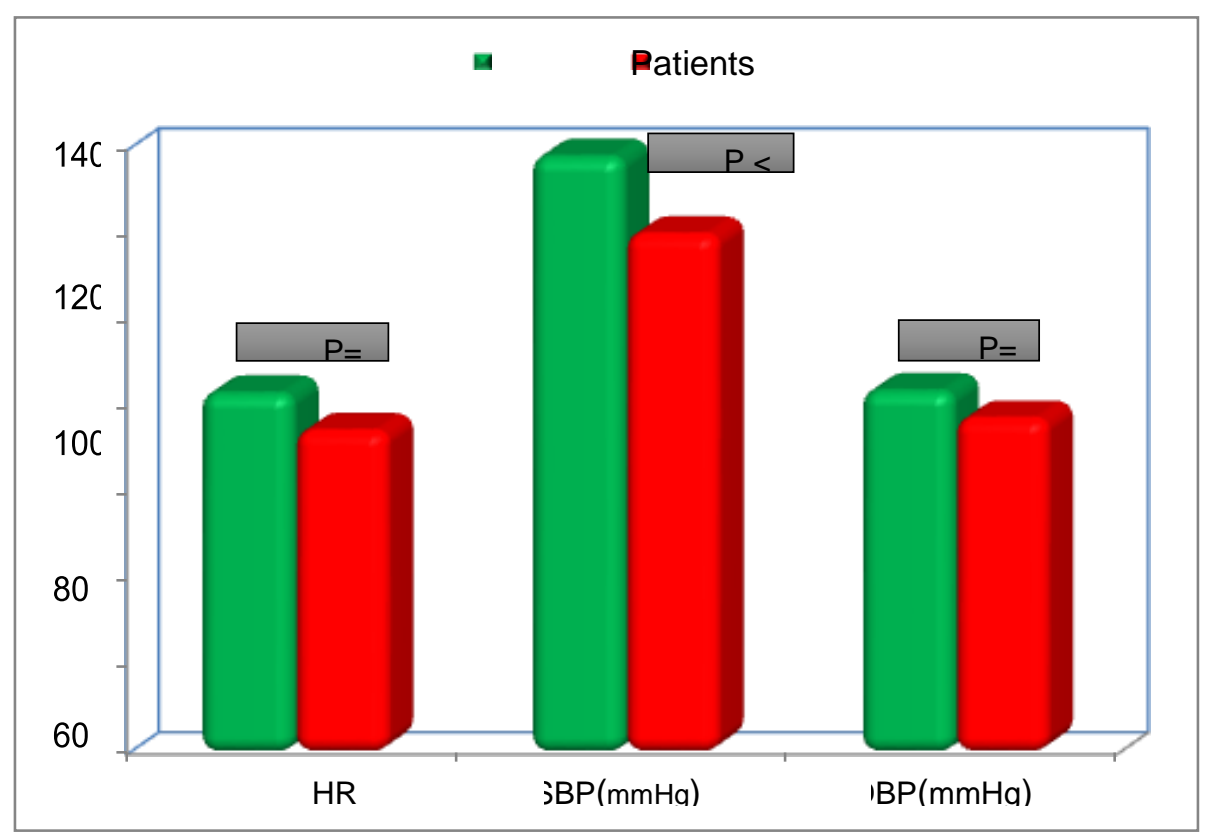

Figure (1): Comparison between patients and control according to clinical characteristics at rest.

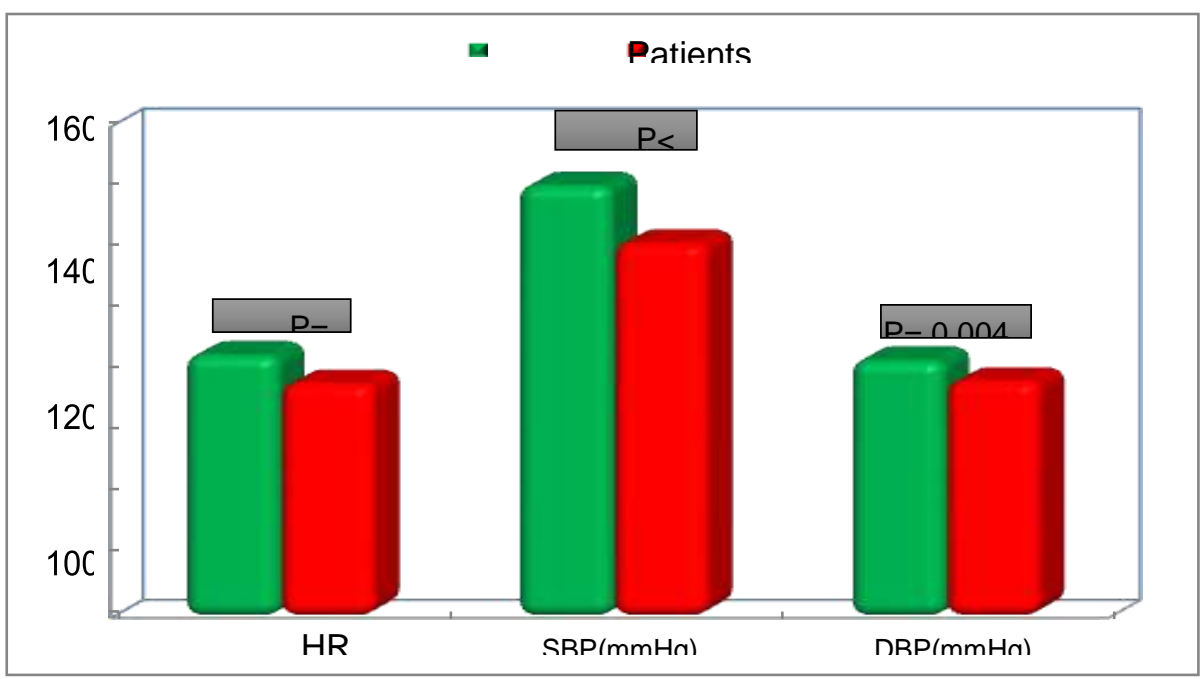

Figure (2): Comparison between patients and control according to clinical characteristics at low dose dobutamine. 


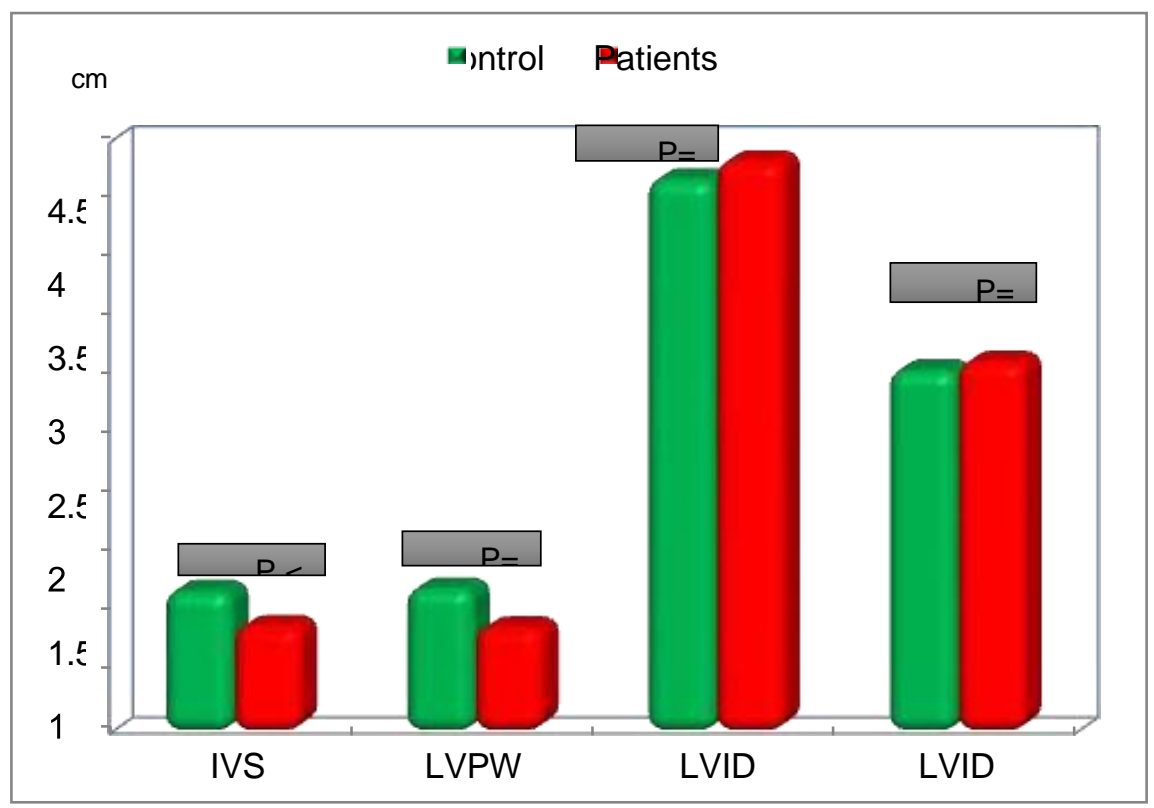

Figure (3): Comparison between patients and control according to resting echocardiographic linear dimensions of LV.

\begin{tabular}{|l|c|c|c|c|}
\hline LV systolic function & $\begin{array}{c}\text { Patients } \\
(\boldsymbol{n}=\mathbf{4 0})\end{array}$ & $\begin{array}{c}\text { Control } \\
(\boldsymbol{n}=\mathbf{2 0})\end{array}$ & t-test & p-value \\
\hline EF\% & $61.82 \pm 5.08$ & $61.43 \pm 4.41$ & & \\
Mean \pm SD & $52.8-76$ & $53.2-70$ & 0.085 & 0.771 \\
Range & $-18.08 \pm 1.63$ & $-20.50 \pm 1.52$ & & \\
\hline GLS \% & $-21.5 \_-14.7$ & $-25.2 \_-18.8$ & 30.921 & $<0.001 * *$ \\
Mean \pm SD & &
\end{tabular}

P-value $>0.05 \mathrm{NS} ; *$ p-value $<0.001 \mathrm{HS}$

T-Independent Sample t-test;

Table (1): Comparison between patients and control according to resting echocardiographic characteristics of LV systolic function.

\begin{tabular}{|c|c|c|c|c|}
\hline $\begin{array}{c}\text { Low Dose Dob } \\
\text { Echo }\end{array}$ & $\begin{array}{c}\text { Patients } \\
(n=40)\end{array}$ & $\begin{array}{c}\text { Control } \\
(n=20)\end{array}$ & t-test & p-value \\
\hline $\begin{array}{c}\text { EF\% } \\
\text { Mean } \pm \text { SD } \\
\text { Range }\end{array}$ & $\begin{array}{c}65.46 \pm 5.08 \\
55.2-78\end{array}$ & $\begin{array}{c}64.35 \pm 5.68 \\
56.5-75.2\end{array}$ & 1.020 & 0.311 \\
\hline $\begin{array}{c}\text { GLS } \\
\text { Mean } \pm \text { SD } \\
\text { Range }\end{array}$ & $\begin{array}{c}-19.11 \pm 1.75 \\
-23.1 \_-15\end{array}$ & $\begin{array}{l}-22.61 \pm 1.88 \\
-28.5 \_-20.2\end{array}$ & 8.682 & $0.008 *$ \\
\hline
\end{tabular}

P-value $>0.05 \mathrm{NS} ; *$ p-value $<0.05 \mathrm{~S}$

T-Independent Sample t-test;

Table (2): Comparison between patients and control according to echocardiographic characteristics of LV systolic function at low dose dobutamine. 


\section{Discussion}

The current study conducted to assess the value of measuring GLS at rest and at low dose dobutamine to detect subclinical LV systolic dysfunction in patients with systemic hypertension.

This prospective observational study conducted from June 2019 to April 2020 and included 60 individuals, 40 patients were hypertensives and 20 normotensives control group.

Matle, et al. ${ }^{7}$, Imbalzano, et al., ${ }^{8}$ and Hensel et al. ${ }^{9}$ were concerned with this issue in their studies. Matle et al, ${ }^{7}$ enrolled 129 patients in their study, 73 were hypertensives and 56 as a healthy control group with an average age $60.0 \pm 8.7$ and $56.7 \pm 10.2$ respectively. with no significant differences betwwen the 2 groups according to either the age $(\mathrm{P}=0.051)$ or sex ( $\mathrm{P}$ $=0.294$ ). Imbalzano, et al. ${ }^{8}$, included in 102 patients their study, 51 patients with isolated hypertension (33 males, mean age $56.5 \pm 14$ years) and 51 age and gender-matched healthy subjects ( 32 males, mean age $52 \pm 13$ years). According to the presence or absence of $\mathrm{LVH}$, patients were classified as $\mathrm{LVH}(+)$ and $\mathrm{LVH}(-)$, respectively. Hensel et $\mathrm{al}^{9}$, enrolled 46 hypertensives with an average age $46.6 \pm 14.4$, and 46 healthy controls with an average age $44 \pm 22.5$, with no significant differences between the 2 groups according to either the age or sex. We used normotensive patients with comparable cardiovascular risk factors and we excluded patients with diabetes, significant coronary artery disease, non-sinus rhythm, left bundle branch block, coexisting significant left sided valvular heart disease (more than mild in severity), previous myocardial infarction, or coronary revascularization, therefore were are able to examine GLS in a more homogenous patient population, where the only major factor adversely affecting LV deformation was hypertension. Matle et $\mathrm{al},{ }^{7}$ Imbalzano, et al. ${ }^{8}$, and Hensel et $\mathrm{al}^{9}$ also excluded these patients. Imbalzano, et al. ${ }^{8}$, excluded also dyslipedemic patients.

In our study all patients underwent resting general echocardiographic examination and 2D STE GLS measurement then at low dose dobutamine 2D STE GLS and EF were measured, which is similar to that was done by Matle, et al. 7 Hensel, et al. ${ }^{9}$, measured 2D STE GLS and EF at three different levels of physical challenge, in the resting state, after cycling at a level of 50Watts of resistance for two minutes, and at 150 Watts resistance. Imbalzano, et al. ${ }^{8}$, examined their patients in the resting state only.

The mean HR did not differ significantly between the patients and control groups either at rest $(65.3 \pm 10.5$ $\mathrm{BPM}$ vs.74.90 $\pm 8.04 \mathrm{BPM}$ respectively; $\mathrm{P}=0.477$ ), or at low dose dobutamine $(77.30 \pm 11.76 \mathrm{BPM}$ vs. $64.2 \pm$ 9.0BPM, respectively; $\mathrm{P}=0.350$ ) which is in agreement with Matle et al. ${ }^{7}$ who revealed at rest (75.60 \pm 10.50 BPM vs.74.90 \pm 8.04 BPM respectively; $\mathrm{P}=0.525)$ and at low dose dobutamine $(64.3 \pm$ 11.1BPM vs. $63.0 \pm 9.0 \mathrm{BPM}$, respectively; $\mathrm{P}=0.477$ ) and also concordant with Imbalzano et al. ${ }^{8}$ who reported the mean HR didn't differ significantly between the patients and control groups either hypertensives with LVH (66.6 \pm 9.7 BPM vs. $70 \pm 13 \mathrm{BPM}$, respectively; $\mathrm{P}=\mathrm{NS}$ ) or hypertensives without LVH $(68.8 \pm 9.2$ BPM vs. 70 $\pm 13 \mathrm{BPM}$, respectively; $\mathrm{P}=\mathrm{NS})$. Hensel et al. ${ }^{9}$, reported the mean
HR didn't differ significantly between the patients and control groups either at rest $(69.3 \pm 11.8 \mathrm{BPM}$ vs. 72.4 $\pm 15.1 \mathrm{BPM}$, respectively; $\mathrm{P}=\mathrm{NS}$ ) or at 50 wat stress (110.7 $\pm 11.6 \mathrm{BPM}$ vs. $103 \pm 10.2 \mathrm{BPM}$, respectively; $\mathrm{P}=\mathrm{NS}$ ) but at 150 watt stress mean HR was significantly higher in the control group compared to the hypertensive group $(140.2 \pm 18.1 \mathrm{BPM}$ vs. 124.5 \pm 15.8 BPM, respectively; $\mathrm{P}=0.00$ ).

Our study showed that both the mean of the interventricular septum (IVS) and the left ventricular posterior wall (LVPW) thickness were significantly higher in the patients group compared to the control group (IVS; $1.20 \pm 0.13 \mathrm{~cm}$ vs. $0.90 \pm 0.17 \mathrm{~cm}$ respectively<0.001, LVPW; $1.22 \pm 0.10 \mathrm{~cm}$ vs. $0.89 \pm 0.15 \mathrm{~cm}$ respectively; $\mathrm{P}<0.001$ ) which is consistent with Matle et al. ${ }^{7}$ who revealed (IVS; $1.1 \pm 0.2$ vs. $1.0 \pm 0.2$ and its $p$-value was 0.003 , LVPW; $1.1 \pm 0.1$ vs. $1.0 \pm 0.2$, respectively and its pvalue was 0.001 ) and consistent with Imbalzano et al. 8 showed that both the mean of the inter-ventricular septum and LV posterior wall thickness were significantly higher in the hypertensive group with LVH compared to the control group (IVS; $14 \pm 2.9 \mathrm{~mm}$ vs. $10.2 \pm 1 \mathrm{~mm}$ respectively; $\mathrm{P}<0.001$, LVPW; $12 \pm 1.1$ $\mathrm{mm}$ vs. $7.4 \pm 0.8 \mathrm{~mm}$ respectively; $\mathrm{P}<0.001$ ) but no significant difference between the control group and the hypertensive group without LVH. Hensel et al. ${ }^{9}$, reported that there was significant difference between the hypertensive group and the control group as regard to IVS (IVS; $1 \quad \pm 0.2 \mathrm{~cm}$ vs. $0.9 \pm 0.2 \mathrm{~cm}$ respectively $<0.016$ ) but no significant difference as regard to LVPW $(1.1 \quad \pm 0.2 \mathrm{~cm} \quad$ vs. $1 \quad \pm 0.2 \mathrm{~cm}$ respectively; $\mathrm{P}=\mathrm{NS}$ ).

Our study demonstrated that there was with no significant difference in the mean of LVIDd and LVIDs between the patients group compared to the control group (LVIDd; $4.68 \pm 0.54 \mathrm{~cm}$ vs. $4.83 \pm 0.46$ $\mathrm{cm}$, respectively; $\mathrm{P}=0.297$, LVIDs; $3.07 \pm 0.50 \mathrm{~cm}$ vs. $3.14 \pm 0.39 \mathrm{~cm}$ respectively; $\mathrm{P}=0.386$ ) which is in line with Matle et al. ${ }^{7}$, (LVIDd; $4.6 \pm 0.5 \mathrm{~cm}$ vs. $4.6 \pm 0.4$ $\mathrm{cm}$, respectively; $\mathrm{P}=0.9$, LVIDs; $2.6 \pm 0.4 \mathrm{~cm}$ vs. $2.9 \pm 0.6 \mathrm{~cm}$ respectively; $\mathrm{P}=0.119)$. Hensel et al. ${ }^{9}$, reported that LVIDd significantly higher in the patients group compared to the control group (LVIDd; $5.4 \pm 0.5 \mathrm{~cm}$ vs $4.3 \pm 0.5 \mathrm{~cm}$, respectively; $\mathrm{P}=0.011$ ) while LVIDs did not differ significantly (LVIDs; 3.1 $\pm 0.5 \mathrm{~cm}$ vs. $3 \pm 0.5$ respectively; $\mathrm{P}=\mathrm{NS}$ ).

Our study showed statistically significant increase mean of patients group compared to control group according to $\mathrm{LV}$ mass $(213.51 \pm 47.88 \mathrm{~g}$ vs. $150.87 \pm 38.11 \mathrm{~g}$ respectively<0.001) and LVMI $(118.96 \pm 26.77 \mathrm{~g} / \mathrm{m} 2$ vs. $81.43 \pm 21.70 \mathrm{~g} / \mathrm{m} 2$ respectively: $\mathrm{P}<0.001)$ which is consistent with Hensel et al. ${ }^{9}$, who reported significant increase mean of patients group compared to control group according to LV mass, $(188.4 \pm 59.4 \mathrm{~g}$ vs. $148.8 \pm 44.2 \mathrm{~g}$ respectively; $\mathrm{P}<0.001)$ LVMI, $(96.8 \pm 30.6 \mathrm{~g} / \mathrm{m} 2$ vs. $81.1 \pm 21.3 \mathrm{~g} / \mathrm{m} 2$ respectively: $\mathrm{P}<0.02$ ), also Imbalzano et al. ${ }^{8}$ showed significantly higher mean LVMI of patients with LVH group compared to either control group $(121.8 \pm 16 \mathrm{~g}$ vs. $63.6 \pm 21 \mathrm{~g}$ respectively; $\mathrm{P}=0.001$ ) or patients without $\mathrm{LVH}$ $(121.8 \pm 16$ g vs. $81 \pm 14.5$ g respectively $=0.001)$ also LVMI significantly higher in patients group without LVH compared to the control group $(81 \pm 14.5 \mathrm{~g}$ vs. $63.6 \pm 21$ g respectively; $\mathrm{P}=0.01$ ). 
Our study showed that no significant difference in the mean LVEF between the patients group and the control group either at rest $(61.82 \pm 5.08 \%$ and $61.43 \pm 4.41 \%$ respectively; $\mathrm{P}=0.771$ ) or at low dose dobutamine $(65.46 \pm 5.08 \%$ and $64.35 \pm 5.68 \%$ respectively; $\mathrm{P}=0.311$ ) which is concordant to that reported by Matle et al. ${ }^{7}$, who reported at rest $(64.5 \pm$ $6.0 \%$ and $64.5 \pm 6.6 \%$ respectively; $\mathrm{P}=0.986$ ) and at low dose dobutamine $(72.1 \pm 6.5 \%$ and $71.2 \pm 7.0 \%$ respectively; $\mathrm{P}=0.424$ ), Imbalzano et al. 8, reported no significant difference in the mean resting LVEF between the control group and the hypertensive group either hypertensives with $\mathrm{LVH}(63 \pm 5.9 \%$ and $59 \pm 8 \%$ respectively; $\mathrm{P}=\mathrm{NS}$ ), or hypertensives without $\mathrm{LVH}$ $(63 \pm 5.9 \%$ and $60 \pm 7 \%$ respectively; $\mathrm{P}=\mathrm{NS})$.

Our study revealed LV GLS was significantly lower in the patients group compared to the control group either at rest $(-18.08 \pm 1.63 \%$ vs.$20.50 \pm 1.52$ percentage respectively; $\mathrm{P}<0.001)$ or at low dose dobutamine $(-19.11 \pm 1.75 \%$ vs. $22.61 \pm 1.88 \%$ respectively; $\mathrm{P}=0.008$ ). which is concordant with Matle et al. 7 who revealed at rest ($17.1 \pm 1.8 \%$ vs. $-19.4 \pm 1.5 \%$ respectively $; \mathrm{P}<0.001$ ) and at low dose dobutamine $(-18.1 \pm 2.3 \%$ vs. $-22.6 \pm$ $2.4 \%$, respectively and its p-value was $<0.001)$ and also concordant with Imbalzano et al. ${ }^{8}$ who revealed resting LV GLS significantly lower in hypertensive patients compared to normotensive group, either hypertensives without LVH $(-18 \pm 1.9 \%$ vs. $20.4 \pm 2.5 \%$, respectively; $\mathrm{P}=0.02$ ) or hypertensives with LVH $(-15.9 \pm 3.3 \%$ vs. $-20.4 \pm 2.5$ percentage. Respectively; P <0.001), also LV GLS significantly lower in hypertensive patients with LVH compared to hypertensive patients without LVH ($15.9 \pm 3.3$ percentage vs. $-18 \pm 1.9 \%$. respectively; $\mathrm{P}$ 0.01). Hensel et al. ${ }^{9}$, revealed LV GLS was significantly lower in the patients group compared to the control group either at rest $(-17.8 \pm 2.8 \%$ vs. $20.50 \pm 2.3 \%$ respectively; $\mathrm{P}<0.001)$ or at 50 watt stress (-18.63 $\pm 2.4 \%$ vs. $-20.93 \pm 2.5 \%$ respectively; P $<0.001)$ or at 150 watt stress $(-19.1 \pm 2.4 \%$ vs. $22.13 \pm 3.1 \%$ respectively; $\mathrm{P}<0.001$ ).

\section{Conclusion}

Hypertensive patients have impaired left ventricular global longitudinal strain at rest and at low dose dobutamine despite normal resting left ventricular systolic function assessed by conventional 2DEchocardiography.

Speckle tracking echocardiography increases the sensitivity in detecting subclinical cardiac involvement in early stages of hypertension compared to conventional 2-D echocardiography .

Global longitudinal strain measurement using speckle-tracking echocardiography is advisable to detect subclinical left ventricular systolic dysfunction in hypertensive patients, however, large-scale study is highly recommended to indorse these consequences.

\section{References}

1. Naeije R, Vanderpool R, Dhakal BP, et al. Exercise-induced pulmonary hypertension: physiological basis and methodological concerns. Am J Respir Crit Care Med., 2013;187: 576-583.

2. Chemaly ER, Chaanine AH, Sakata S, et al. Stroke volume- to-wallstress ratio as a loadadjusted and stiffness-adjusted indicator of ventricularsystolic performance in chronic loading. J Appl Physiol., 2012;113:1267-1284.

3. Pellikka PA, Roger VL, Oh JK, et al. Stress echocardiography. Part II. Dobutamine stress echocardiography: Techniques, implementation, clinical applications, and correlations, Mayo Clin Proc., 1995; 70(1):16-27.

4. Magne J, Mahjoub H, Dulgheru R, et al. Left ventricular contractile reserve in asymptomatic primary mitral regurgitation. Eur Heart J., 2014; 35:1608-16.9.

5. Lang RM, Badano LP, Mor-Avi V, et al. Recommendations for cardiac chamber quantification by echocardiography in adults: an update from the American Society of Echocardiography and the European Association of Cardiovascular Imaging. European. Eur Heart $J$ Cardiovasc Imaging, 2015; 16: 233-71.

6. Leung M, Juergens CP, Lo ST, et al. Evaluation of coronary microvascularfunction by left ventricular contractile reserve with low-dose dobutamine echo-cardiography. Euro Intervention, 2014; 9:1202-1209.

7. Matle J, Thomas L, Dominic Y, et al. Left ventricular function and contractile reserve in patients with hypertension. Eur Heart $J$ Cardiovasc Imaging, 2017;19:1253-1259

8. Imbalzano E, Concetta Z, Scipione C, et al. Left Ventricular Function in Hypertension: New Insight by Speckle Tracking Echocardiography. Echocardiography, 2011; 28:649-657.

9. Hensel KO, Jenke A and Leischik R. Speckletracking and tissue- doppler stress echocardiography in arterial hypertension: a sensitive tool for detection of subclinical LV impairment. Biomed Res Int., 2014; 2014: 472562. doi: 10.1155/2014/472562. 